\section{Perspectiva da bioética na relação médico- paciente nos crimes sexuais}

\section{Costa, Thais Albuquerque da}

Grupo de Estudos e Pesquisa em Bioética do Centro Universitário Newton Paiva - GEPBio. E-mail: thais.albc5@gmail.com.

\section{Fernandes, Sarah Abdon Lacerda}

Grupo de Estudos e Pesquisa em Bioética do Centro Universitário Newton Paiva - GEPBio.

\section{Reis, Bianca Izabella Carvalho dos}

Grupo de Estudos e Pesquisa em Bioética do Centro Universitário Newton Paiva - GEPBio.

\author{
Sarsur, Marcelo \\ Grupo de Estudos e Pesquisa em Bioética do Centro \\ Universitário Newton Paiva - GEPBio.

\section{Dadalto, Lucina} \\ Grupo de Estudos e Pesquisa em Bioética do Centro \\ Universitário Newton Paiva - GEPBio.
}

PALAVRAS-CHAVE: médico-paciente, saúde mental, ética médica, crimes sexuais, atendimento hospitalar.

No presente trabalho, pretende-se examinar a aplicação da Lei Federal $n^{\circ} 12.845 / 2013$ no atendimento hospitalar às vítimas de violência sexual, sob a ótica da bioética clínica. $\mathrm{O}$ contato que o paciente/vítima tem com o médico que o atende é de suma importância para que este consiga ressignificar o ato de violência sofrido. Por vezes, a prática médico-hospitalar compreende a violência sexual apenas como crime e deixa de analisar possíveis conflitos mentais do paciente decorrentes do crime. Estudos demonstram que falta preparo dos hospitais e dos médicos para atender e acompanhar o paciente. Deste modo, os tratamentos médicos tradicionais se tornam ineficazes na assistência à vítima de violência sexual. As relações médico-paciente sempre foram pautadas por sensibilidade e respeito. Há na sociedade brasileira uma cultura da violência sexual e, por vezes, ocorre a culpabilização social da própria vítima. A Lei Federal $n^{0} 12.845 / 13$, que dispõe sobre o atendimento obrigatório e integral de pessoas em situação de violência sexual, possui como finalidade tornar diferenciado $\mathrm{o}$ atendimento a tais ofendidos. A referida lei tentou trazer respostas jurídicas para uma questão de saúde e social, deixando lacunas no tratamento a ser utilizado. Sob essa perspectiva, cumpre salientar a autonomia como princípio bioético primordial nas relações médico-paciente. Com isso, visa-se a conscientizar a vítima acera de seu poder de escolher os tratamentos médicos, com a ajuda do profissional médico. A própria lei já lista quais os tratamentos médicos podem ser escolhidos, sendo um dever e responsabilidade do médico informar ao paciente/vítima seu poder de escolha, independentemente de suas objeções de consciência, pois é assim que a autonomia da vítima será exercida. Significa, também, que não deve haver hipóteses de cerceamento sobre a autonomia do paciente/vítima. Sob essa perceptiva, reiterase a importância do primeiro contato do médico com a paciente/vítima, pois ao fazê-la se sentir compreendida e segura, a autonomia vai surgir e, a vítima vai começar a entender o que é melhor para recuperar a sua saúde mental e física. Por fim, ao trazer a perspectiva da bioética na relação médico-paciente para os crimes sexuais, deve-se por em destaque os pontos controversos a respeito do tratamento da vítima, evitando um conflito entre a autonomia do paciente e responsabilidade médica. O tratamento das vítimas deve ser diferenciado, e utilizando os princípios bioéticos na relação médico-paciente, tende-se a conseguir resultados mais adequados. Indica-se como marco teórico, a princípio, o Código Penal Brasileiro, a Lei Federal $n^{\circ} 12.845 / 2013$ e as bases da bioética principiológica, e conclui o trabalho que ainda existem obstáculos no tratamento diferenciado das vítimas de crimes sexuais.

AGRADECIMENTOS. Agradecemos a todos que de alguma forma contribuíram para a realização desta pesquisa, mesmo com toda a dificuldade encontrada para produção acadêmica científica nesse país. Em especial aos Coordenadores do GEPBio, por acreditarem no nosso potencial.

\section{REFERÊNCIAS:}

[1] AZEVEDO, Renata Cruz Soares de; COSTA, Fabrício Donizete da. Empatia, relação médico-paciente e formação em medicina: um olhar qualitativo. Disponível em: < http://www.scielo.br/pdf/rbem/v34n2/a10v34n2.pdf> Acesso em: 19 de ago. de 2018.

[2] BRASIL. Lei $n^{\circ} 12.845$, de $1^{\circ}$ de agosto de 2013. Disponível em: < http://www.planalto.gov.br/ccivil_03/_Ato20112014/2013/Lei/L12845.htm> Acesso em: 26 de ago. de 2018.

[3] CONSELHO REGIONAL DE MEDICINA DO ESTADO DE SÃO PAULO. Relação médico-paciente- Um encontro. São Paulo: Conselho Regional de Medicina do Estado de São Paulo, 2017. 160 p.

[4] JUNQUEIRA, Cilene Rennó. Bioética. Disponível em: < https://www.unasus.unifesp.br/biblioteca_virtual/esf/2/unidades_co nteudos/unidade18/unidade18.pdf> Acesso em: 11 de ago. de 2018.

[5] UNESCO. Declaração Universal de bioética e direitos humanos. Disponível em: < http://unesdoc.unesco.org/images/0014/001461/146180por.pdf> Acesso em: 12 de ago. de 2018. 